\begin{tabular}{|c|c|}
\hline$E$ & 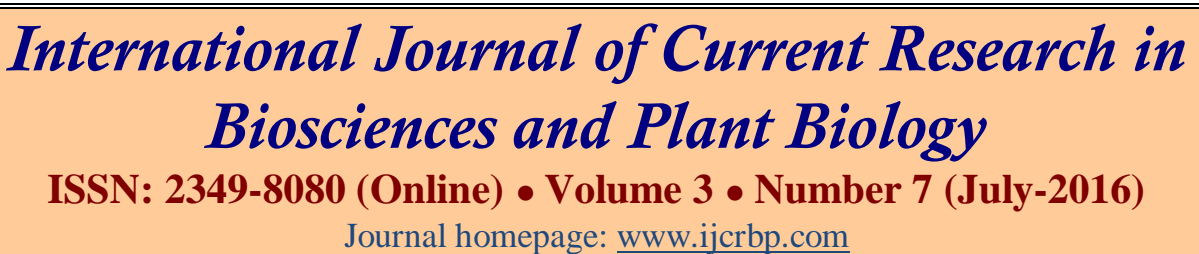 \\
\hline
\end{tabular}

\title{
Quantitative Yield and Monetary Losses of Two Sugar Cane Varieties Caused by Whip Smut (Sporisorium scitamineum H. \& P. Sydow) in Nigeria
}

\author{
Akaamaa C. Wada ${ }^{*}$, Akachukwu B. Anaso ${ }^{2}$ and Bernard O. Ehirim ${ }^{1}$ \\ ${ }^{1}$ National Cereals Research Institute, P.M.B 8, Bida, Niger State, Nigeria \\ ${ }^{2}$ Department of Crop Protection, University of Maiduguri, Maiduguri, Nigeria
}

*Corresponding author.

\section{Abstract}

The yields of two sugar cane varieties Bida local and Co 957 were reduced by varying concentrations of Sporisorium scitamineum [M. Piepenbr., M. Stoll \& Oberw. 2002 (Syn: Ustilago scitamiea H. \& P.Sydow)], the causal organism for whip smut of sugar cane at Badeggi (lat. $9^{\circ} 045^{\prime}$ long. $6^{\circ} 07^{\prime} \mathrm{E}$ at an altitude of $70.57 \mathrm{~m}$. a. s. 1). The two varieties of sugar cane were inoculated with four levels of $S$. scitamineum inoculum, $0 \times$ $10^{6}, 2 \times 10^{6}, 4 \times 10^{6}$ teliospores $/ \mathrm{ml}$ respectively and planted in a split plot design in four replicates between 1998 and 2000. Results showed that their yields were significantly impaired by the effect of whip smut. The $6 \times 10^{6}$ teliospores $/ \mathrm{ml}$ inoculum concentration recorded the least yield in the two test cane varieties. The yields of Bida local in all the two crop cycles from 1998 to 2000 were significantly lower than the yields of Co 957. Regressions of whip smut incidence on cane yields of Co 957 and 'Bida local' for two crop cycles showed that in both years, there was significant negative correlation between the incidence of whip smut and cane yield, except in 2000 on Co 957 ratoon crop. The highest yield reduction by whip smut was from the plant crop of Co 957 in 1998 and the ratoon crop of 'Bida local' in 1999 where each unit rise in whip smut incidence caused cane yield reduction of between 1.00-1.9 t/ha and 0.1-1.9 t/ha in Co 957 and 'Bida local' respectively. In monetary terms and at current rate of 1US\$ to 200 Nigerian Naira (N200), the cane grower of the two cane types looses between $\$ 600$ $1140 / \mathrm{t}$ or N120,000-228,000 for Co 957 and $\$ 60-1140$ or N12000-228,000 for 'Bida local' chewing cane. In the 1999 evaluation, each unit rise in incidence of whip smut reduced the yield of Co 957 by 0.4-0.6 t/ha which resulted in the cane grower of the two type sugar cane losing $\$ 240-360 / \mathrm{t}$ or N144, 000-216,000 for Co 957 and by 1.1-1.9 t/ha resulting in $\$ 660-1140$ loss/t or N132, 000-684,000 for 'Bida local' respectively in the 1999-2000 crop cycles.
\end{abstract}

\section{Article Info}

Accepted: 10 June 2016

Available Online: 06 July 2016

\section{Keywords}

Chewing and industrial sugar cane Crop cycles

Heavy inoculum loads

Ratoon canes

Teliospores

\section{Introduction}

Sugar cane is a tropical grass belonging to the $\mathrm{C}_{4}$ - group. A planted stem cutting usually produces a primary stalk (or stem) around which secondary and tertiary tillers are produced resulting into a clump known as a cane stool.
Each of the cane stalks/tillers may attain a height of 2-3 m with a diameter of 2-6 cm. The stalks are ready for harvest at 12-24 months after planting. Regrowths from the first harvest produce new stalks known as ratoon stalks and their harvest is known as ratoon harvest. The ratoons take shorter duration to mature 10 -18 months (Akobundu, 1987). 
Sugar cane is propagated by stem cuttings called setts, each of which has about three nodes. The cuttings are planted at least $5 \mathrm{~cm}$ deep, laid end to end in a row and $1.0-1.5 \mathrm{~m}$ apart in plantation (Akobundu, 1987) or in slanting position at a distance of $1 \mathrm{~m}$ apart by chewing cane farmers. Two types of sugar cane are grown in Nigeria: the noble or thick canes and the thin canes (Akobundu, 1987). The noble thick type is also known as chewing or rain fed sugar cane and yields higher than the harder thin type almost exclusively grown in plantation estates. The smallholder farmers grow sugar cane on average farm sizes of $0.2-0.5$ ha all over Nigeria. Smallholder farmers are reported to achieve yields of between 35-50 t/ha, while the average yield of sugar cane in estates varies from 50-100 t/ha with supplementary irrigation (Akobundu, 1987).

Steady production of sugar cane by both sugar estates and smallholder farmers has been constrained by biotic factors posed by pests and diseases. Many sugar cane diseases and pests reported in different parts of the world have also been reported in Nigeria (Wada, 1997; Sivanesan and Waller, 1986; Boboye, 1986). They include whip smut, red rot, leaf blast, sugar cane mosaic, pineapple disease, ratoon stunting disease, leaf scald, mottled stripe, pokkal boeng, sugar cane wilt disease (Sivanesan and Waller, 1986; Wada et al., 1999a). Wada (1997) and Wada et al. (1998 and 1999b) listed whip smut as the most important disease of sugar cane in Nigeria.

Whip smut is the most widespread disease of sugar cane and has been of importance at one time or another in many sugar cane growing areas (Bebee, 1988, Sivanesan and Waller, 1986; Indi et al., 2012). Whip smut is a serious disease of sugar cane and reaches epidemic proportions where susceptible cultivars are grown (Villalon, 1982). Whip smut, therefore, causes significant quantitative losses to cane growers worldwide (Indi et al., 2012).

Bebee (1988) and Brar (1988) indicated that four smut diseases of sugar cane are recognized namely: Floral smut caused by Sphacelotheca cruenta (Kuehn) Potter, covered smut caused by Sphacelotheca macrospora Yen and Wang. False floral smut caused by species of (Claviceps and Epicoceum) and culmicolus smut also called whip smut, caused by the basidiomycete fungus Sporisorium scitamineum Sydow) [M. Piepenbr., M. Stoll \& Oberw. 2002 (Syn: Ustilago scitamiea H. \& P.Sydow)] is asserted by Brar (1988) as the most widespread and most important in many sugar cane growing areas of the world.
Of the four smut diseases, whip smut (S. scitamineum) has been the most widespread disease of sugar cane, causing insignificant to significant quality and yield losses in several sugar cane growing areas of the world (Antonie, 1961, Comstock et al., 1987 and Comstock, 2014).

Walker (1987) reported that the life cycle of smut takes months rather than weeks which results in changes in patterns of successive ratoons. Walker (1987) further gives a description on smut infection and reported that it occurred only through the buds, with younger buds showing higher susceptibility than older ones. The shoot is infected at the beginning or just at the commencement of growth through air borne spores (Antonie, 1961, Hill and Waller, 1988). A relatively high number of spores is required on the bud surface for infection to occur and under field conditions where air borne spores were present, spores were deposited on the leaves and were washed down the stem by rain (Walker, 1987). The youngest buds and the terminal meristem were protected from such deposition. Following infection of buds, $S$. scitamineum may remain dormant until apical dominance is weakened or until the bud is used for planting (Walker, 1987; Comstock et al., 1987; Pearse, 1989). The infected apical meristem then usually gives rise to a whip after the emergence of the six or so leaves that are pre-formed in the bud; resulting in the leading shoot being healthy but the secondary and lateral tillers being infected (Hill and Waller, 1988).

Buds at the soil surface are also readily infected by spores deposited in dry weather, for example shoots arising from buds deep below ground level are likely to be less infected. This gives rise to the common situation noticed in ratoons where some stalks of a stool are heavily smutted but other tillers are normal (Walker, 1987; Hill and Waller, 1988, Comstock, 2014).

Once inside the stalk, the fungus may develop hyphae and infect more buds and the apical meristem, giving rise to terminal whips in older canes (Walker, 1987; Hill and Waller, 1988). The detection of internal infection is difficult, but is important in determining the ultimate degree of susceptibility and yield loss by smut (Walker, 1987; Magarey et al., 2014).

Irvine (1982) and Bebee (1988) observed that accurate assessment of the damage caused by smut is not easy. Generally, damage assessments have been more in terms of the percentage of shoots and stools affected than of loss in yield. However, quantitative and qualitative forms 
of damage caused to cane by $S$. scitamineum have been reported from across the world (Comstock, 2014; Indi et al., 2012; Kumar et al., 1989; Hoy et al., 1986; Padmanaban et al., 1986; Msechu and Keswani, 1982; Whittle, 1982).

In Nigeria, S. scitamineum is also the most important sugar cane disease (Obakin, 1978; Wada, 1997). Whip smut was reported to be responsible for the discontinued cultivation of the commercial variety D141/46 by the then Nigerian Sugar Company (NISUCO), Bacita in 1978 (Ogunwolu, 1986). There have been no detailed studies carried out to investigate quantitative and monetary losses caused on sugar cane to cane growers in the country. In order to bridge this gap in knowledge and provide sugar cane growers with information on the quantitative tonnage and monetary losses incited by whip smut, the present study was, therefore, set up to investigate the effects of varying concentrations of $S$. scitamineum on the two cane varieties and the extent of tonnage yield and monetary losses caused to them by the fungus.

\section{Materials and methods}

Two experiments were conducted between 1998 and 2000 at the sugar cane research field at Badeggi (lat. $9^{\circ} 045^{\prime} \mathrm{N}$; long $6^{\circ} 07^{\prime} \mathrm{E}$ at an altitude of $70.57 \mathrm{~m}$. a. s. 1) to determine the quantitative and monetary losses on the yields of two sugar cane varieties caused by different whip smut (S. scitamineum) inoculum concentrations.

\section{Smut teliospores preparation}

Fresh smut whips were collected from the field of a Bida local cane in the early hours of each morning for three days. These were dried under shade for one hour, scrubbed with hands covered with sterilized gloves to obtain smut teliospores, and then sieved using $53 \mu \mathrm{m}$ mesh. The sieved teliospores were weighed out in three categories of $10 \mathrm{~g}, 20 \mathrm{~g}$ and $30 \mathrm{~g}$ and sealed in cellophane bags and stored in the refrigerator in the laboratory for inoculation process at a later date as described by Nasr (1977).

\section{Preparation of planting setts}

Cane cuttings of variety Co 957 and Bida local cane were made from 7 months old canes. The stalks were detrashed to expose the buds. The stalks were then cut into 3 budded setts and subjected to hot water treatment at $52^{\circ} \mathrm{C}$ for 30 minutes in separate batches until the whole planting setts were heat-treated. The cane setts were then separated into groups of 120 stalks each representing the four treatments of 30 setts per treatment following the method of Nasr (1977).

\section{Preparation of smut teliospores suspension and inoculation}

The 10, 20 and $30 \mathrm{~g}$ smut teliospores earlier weighed out and stored in cellophane bags were each emptied into separate 50 litres of sterile water in three different inoculating containers. These were vigorously stirred to obtain a homogenous suspension of the teliospores' corresponding to 2,4 and $6 \mathrm{~g}$ teliospores litre $^{-1}$ which gave haemocytometer values of $2 \times 10^{6}, 4 \times 10^{6}$ and $6 \times$ $10^{6}$ teliospores $/ \mathrm{ml}$ concentrations. The cane cuttings were then immersed in each of these three-teliospore concentrations for 1 hour and then incubated overnight in wet sterile gunny jute bags and kept under the shade as described by Nasr (1977). They were then removed and planted in $5 \mathrm{~m} \times 5 \mathrm{~m}$ plots in the field. There was uninoculated control for each of the two varieties.

\section{Planting of the field trial for yield loss assessment}

Each treatment $\left(2 \times 10^{6}, 4 \times 10^{6}\right.$ and $6 \times 10^{6}$ teliospores $/ \mathrm{ml}$ concentrations and the control from the 4 groups) was taken to the field in the sterile jute bags and planted in shallow furrows on flat ground. The two varieties treated with hot water were planted in main plots; while those inoculated with the different teliospore concentrations $\left(0.2 \times 10^{6}, 4 \times 10^{6}\right.$ and $6 \times 10^{6}$ teliospores $\left./ \mathrm{ml}\right)$ were tested in sub plots in a split plot design with four replicates randomized using a table of random numbers. Each plot consisted of six- $5 \mathrm{~m}$ rows and $1 \mathrm{~m}$ apart, and the planting setts were laid continuously end-to-end, thus giving no intra-row spacing. The study lasted for two overlapping croppings consisting of two-plant cane (PC) (one each in 1998 and 1999) and two - ratoon canes (RC) (first ratoon of each trial in 1999 and 2000).

The 1999 trial was established in a separate field adjacent to the 1998 trial. Normal agronomic practices were carried out at the required growth stages of the canes till harvest.

Percent smutted stools and stalks were calculated by first counting the total number of stools and stalks in a plot using a tally counter. Then the number of smutted stools and stalks in the same plot was counted and expressed as a percentage of the total to determine the incidence of whip smut at 3, 6, 9 and 12 MAP or MAR. 


\section{Determination of quantitative yield loss}

Yield loss of sugar cane caused by whip smut was determined by the method of James (1983) from the following relation:

Yield loss $(\%) \frac{\text { Kg wt.of healthy canes }-\mathrm{Kg} \text { wt. of smutted canes }}{\mathrm{Kg} \text { wt. of healthy canes }} \times 100$

\section{Data collection}

Observation and data collection were made on days to first smut whip appearance, percent smutted stools/stalks at 3 and 5 months after planting or ratooning (MAP or MAR) using four inner rows of each plot (net plot) for percent smutted stools and stalks at 3, 6, 9 and 12 months after planting (MAP). The same procedure for data collection was followed for the first ratoon crop at 3, 6, 9 and 12 months after ratooning (MAR).

\section{Data analysis}

All collected data were subjected to analyses of variance (ANOVA), correlation and regression analysis were done using the Analytical Software, 1989, Statisticx Version 3.1 (SX) and means were separated using standard error (SE) and Duncan's Multiple Range Test (DMRT).
The following regression analyses were carried out:

a. Relationship between the incidences, of whip smut and cane yield. This was meant to estimate losses due to whip smut of sugar cane.

b. Relationship between the incidences of whip smut on cane yield in two crop cycles. This was meant to estimate losses due to whip smut in each of the two evaluations.

\section{Results}

Disease and yield assessments: Effects of inoculum concentration and sugar cane variety on incidence and yield, 1998 plant crop

Table 1 shows that in 1998, there was highly significant $(p=0.01)$ decrease in the yields of the two test canes. Bida local recorded significantly lower yield than Co 957. The test canes were worst affected with the highest $6 \times 10^{6}$ teliospores $/ \mathrm{ml} \quad S$. scitamineum inoculum concentration thus recording the least yield as against the significantly highest yield recorded by the check variety. At 3, 6, 9 and 12 MAP, there was significantly higher incidence of smutted stools of Bida local than Co 957.

Table 1. Effects of variety and inoculum concentration on smut incidence and cane yield, 1998 plant crop.

\begin{tabular}{|c|c|c|c|c|c|}
\hline \multirow{2}{*}{ Treatment } & \multicolumn{5}{|c|}{ \% Smutted stools } \\
\hline & 3 MAP & 6 МАР & 9 МАР & 12 MAP & Yield (t/ha) \\
\hline \multicolumn{6}{|l|}{ Variety $(V)$} \\
\hline Co 957 & $5.4 \mathrm{~b}$ & $9.8 \mathrm{~b}$ & $10.7 \mathrm{~b}$ & $12.4 \mathrm{~b}$ & $115.3 \mathrm{a}$ \\
\hline Bida local & $12.6 \mathrm{a}$ & $17.3 \mathrm{a}$ & $17.1 \mathrm{a}$ & $18.3 \mathrm{a}$ & 82.4ab \\
\hline Mean & 9.0 & 13.6 & 13.9 & 15.4 & 98.9 \\
\hline $\mathrm{SE} \pm$ & 1.30 & 1.30 & 1.60 & 1.70 & 11.5 \\
\hline Sig. & $* *$ & $* *$ & $*$ & * & NS \\
\hline \multicolumn{6}{|c|}{ Inoculum concentration (I) (teliospores $\mathbf{d} / \mathbf{m l})$} \\
\hline 0.0 & $0.0 \mathrm{~d}$ & $0.0 \mathrm{~d}$ & $0.0 \mathrm{~d}$ & $0.0 \mathrm{~d}$ & $117.9 \mathrm{a}$ \\
\hline $2 \times 10^{6}$ & $5.3 c$ & $9.9 \mathrm{c}$ & $10.6 c$ & $12.5 \mathrm{c}$ & 106.2ab \\
\hline $4 \times 10^{6}$ & $10.9 \mathrm{~b}$ & $17.5 b$ & $18.2 \mathrm{~b}$ & $19.8 \mathrm{~b}$ & $98.6 a b$ \\
\hline $6 \times 10^{6}$ & $19.7 \mathrm{a}$ & $26.8 \mathrm{a}$ & $26.8 \mathrm{a}$ & 29.1a & $72.6 b$ \\
\hline Mean & 9.0 & 13.4 & 13.9 & 15.4 & 98.8 \\
\hline $\mathrm{SE} \pm$ & 1.70 & 2.10 & 1.40 & 1.70 & 12.0 \\
\hline Sig. & $* *$ & $* *$ & $* *$ & $* *$ & $* *$ \\
\hline \multicolumn{6}{|l|}{ Interaction } \\
\hline $\mathrm{V} \times \mathrm{I}$ & $* *$ & $* *$ & $* *$ & $* *$ & NS \\
\hline
\end{tabular}

Means followed by similar letter(s) are not significantly different at $p=0.01, p=0.05$ according to Duncan's Multiple Range Test $($ DMRT); Sig. $=$ significance, NS $=$ Not significant, $*=$ Significant at $p=0.05, * *=$ Significant at $p=0.01$.

The same Table also shows that in 1998, at 3, 6, 9 and 12 MAP, there was highly significant $(p=0.01)$ increase on incidence of whip smut on sugar cane stools with increase in inoculum concentration. There was highly significant $(p=0.01)$ interaction of variety and inoculum concentration on incidence of smutted stools. Table 1 
also shows that a similar result on smutted stalks in respect of increase in inoculum concentration, except that at 3 MAP, the differences between incidence of smut on stalks following application of inoculum concentration of $6 \times 10^{6}$ and $4 \times 10^{6}$ teliospores $/ \mathrm{ml} 4 \times 10^{6}$ and $2 \times 10^{6}$ teliospores $/ \mathrm{ml}$ and $2 \times 10^{6}$ teliospores $/ \mathrm{ml}$ and check were not significant. Similarly, incidence of smut on stalks on the two varieties was not significantly different at 3,9 and 12 MAP, but significant only at 6 MAP. Similarly, interaction of variety and inoculum concentration on the incidence of whip smut on stalks was significant only at $6 \mathrm{MAP}$ as inoculum concentration increased. There was no significant interaction of variety and inoculum concentration on cane yield.
Effects of inoculum concentration and sugar cane variety on whip smut incidence and yield, 1999 ratoon crop

Table 2 shows that in 1999 at 3 and 6 MAR, there was highly significant $(p=0.01)$ incidence of smutted stools of Bida local than Co 957, but no significant difference on disease incidence was observed at 9 and 12 MAR between the two varieties. At 3,6, and 9 MAR, there were highly significant $(p=0.01)$ increase on disease of whip smut on sugar cane stools with increase in inoculum concentration, except that at 12 MAR the difference in incidence of whip smut on stools was not significant.

Table 2. Effects of variety and inoculum concentration on smut incidence and cane yield, 1999 ratoon crop.

\begin{tabular}{|c|c|c|c|c|c|}
\hline \multirow{2}{*}{ Treatment } & \multicolumn{5}{|c|}{ \% Smutted stools } \\
\hline & 3 MAR & 6 MAR & 9 MAR & 12 MAR & Yield (t/ha) \\
\hline \multicolumn{6}{|l|}{ Variety (V) } \\
\hline Co 957 & $22.3 b$ & $26.0 \mathrm{~b}$ & $27.2 \mathrm{a}$ & $31.0 \mathrm{a}$ & $49.5 \mathrm{a}$ \\
\hline Mean & 30.7 & 34.3 & 28.9 & 33.3 & 44.3 \\
\hline $\mathrm{SE} \pm$ & 2.80 & 2.30 & 7.7 & 8.10 & 0.90 \\
\hline 0.0 & $2.2 \mathrm{~d}$ & $4.4 d$ & $24.6 b$ & $28.5 \mathrm{a}$ & $56.2 \mathrm{a}$ \\
\hline $2 \times 10^{6}$ & $22.5 \mathrm{c}$ & $26.3 c$ & $25.8 \mathrm{ab}$ & $29.1 \mathrm{a}$ & $48.1 \mathrm{~b}$ \\
\hline $4 \times 10^{6}$ & $39.0 \mathrm{~b}$ & $44.1 b$ & $19.6 b$ & $30.7 \mathrm{a}$ & $42.4 \mathrm{c}$ \\
\hline $6 \times 10^{6}$ & $58.8 \mathrm{a}$ & $62.5 \mathrm{a}$ & $45.4 \mathrm{a}$ & $44.7 \mathrm{a}$ & $30.3 d$ \\
\hline Mean & 30.7 & 34.3 & 28.9 & 33.3 & 44.3 \\
\hline
\end{tabular}

Means followed by similar letter(s) are not significantly different at $p=0.01, p=0.05$ according to Duncan's Multiple Range Test $(\mathrm{DMRT}) ;$ Sig. $=$ significance, $\mathrm{NS}=$ Not significant, $*=$ Significant at $p=0.05, * *=$ Significant at $p=0.01$.

The same table shows that incidence of smut on stalks on the two varieties was highly significant $(p=0.01)$ at 3 and 6 MAR, but not at 9 and 12 MAR. A similar result was obtained on smutted stalks in respect of inoculum concentration at 3, 6, 9 and 12 MAR. There was highly significant $(p=0.01)$ interaction of variety and inoculum concentration at 3 and 6 MAR respectively, but not at 9 and 12 MAR.

The yield of Bida local was significantly lower than that of Co 957. Similarly, Table 2 also shows that in 1999, there was highly significant $(p=0.01)$ decrease in yield as inoculum concentration increased. The $6 \times 10^{6}$ teliospores $/ \mathrm{ml}$ inoculum concentration produced significantly the least cane yield. Interaction of variety and inoculum concentration was, however, not significant.
Effects of inoculum concentration and sugar cane variety on whip smut incidence and yield, 1999 plant crop

Table 3 shows that incidence of smut on stools on the two varieties was not significantly different at 9 and 12 MAP, but was significant at 3 and 6 MAP. On the other hand, for the 1999PC, there was highly significant $(p=0.01)$ increase in disease of whip smut on sugar cane stools with increase in inoculum concentration only at 6 MAP. AT 3, 9 and 12 MAP, the difference between the incidence of smutted stools following application of inoculum concentration of $6 \times 10^{6}, 4 \times 10^{6}$ and $2 \times 10^{6}$ teliospores $/ \mathrm{ml}$ and check was not significant. Interaction of inoculum concentration and variety on the incidence of whip smut on stools was not significant. 
Table 3. Effects of variety and inoculum concentration on smut incidence and cane yield, 1999 plant crop.

\begin{tabular}{|c|c|c|c|c|c|}
\hline Treatment & $\begin{array}{l}\text { \% Smut } \\
3 \text { MAP }\end{array}$ & 6 MAP & 9 MAP & 12 MAP & Yield (t/ha) \\
\hline \multicolumn{6}{|l|}{ Variety $(\mathbf{V})$} \\
\hline Co 957 & $0.3 b$ & $16.4 \mathrm{~b}$ & $53.5 \mathrm{a}$ & $50.2 \mathrm{a}$ & $85.0 \mathrm{a}$ \\
\hline Bida local & $3.9 a$ & $38.4 \mathrm{a}$ & $62.8 \mathrm{a}$ & $61.2 \mathrm{a}$ & $45.7 b$ \\
\hline Mean & 3.1 & 28.9 & 58.2 & 55.7 & 64.4 \\
\hline $\mathrm{SE} \pm$ & 0.6 & 7.10 & 5.10 & 4.90 & 2.60 \\
\hline Sig. & $* *$ & $*$ & NS & NS & $* *$ \\
\hline \multicolumn{6}{|c|}{ Inoculum concentration (I) (teliospores/ml) } \\
\hline 0.0 & $1.1 \mathrm{a}$ & $14.3 \mathrm{c}$ & $55.7 \mathrm{a}$ & $50.6 \mathrm{a}$ & $81.9 a$ \\
\hline $2 \times 10^{6}$ & $1.6 \mathrm{a}$ & $28.3 \mathrm{a}$ & 58.1a & $52.0 \mathrm{a}$ & $68.5 b$ \\
\hline $4 \times 10^{6}$ & $2.3 a$ & $27.2 \mathrm{~b}$ & $54.1 \mathrm{a}$ & $56.8 \mathrm{a}$ & $59.0 \mathrm{bc}$ \\
\hline $6 \times 10^{6}$ & $3.3 \mathrm{a}$ & $39.9 a$ & $64.7 \mathrm{a}$ & $63.3 \mathrm{a}$ & $52.2 \mathrm{c}$ \\
\hline Mean & 2.1 & 27.9 & 58.2 & 55.7 & 65.8 \\
\hline $\mathrm{SE} \pm$ & 0.90 & 4.20 & 10.30 & 10.00 & 3.80 \\
\hline Sig. & NS & $* *$ & NS & NS & $* *$ \\
\hline \multicolumn{6}{|l|}{ Interaction } \\
\hline $\mathrm{V} \times \mathrm{I}$ & NS & NS & NS & NS & $* *$ \\
\hline
\end{tabular}

Means followed by similar letter(s) are not significantly different at $p=0.01, p=0.05$ according to Duncan's Multiple Range Test $(\mathrm{DMRT}) ;$ Sig. $=$ significance, NS $=$ Not significant, $*=$ Significant at $p=0.05, * *=$ Significant at $p=0.01$.

Table 3 shows that the yield of the two varieties was significantly different from each other, with Bida local producing lower yield than Co 957. Similarly, the 1999PC gave highly significant $(p=0.01)$ decreased yield as inoculum concentration increased. The differences between the yield of cane following application of inoculum concentration of $6 \times 10^{6}$ and $4 \times 10^{6}$ teliospores $/ \mathrm{ml}, 4 \times 10^{6}$ and $2 \times 10^{6}$ teliospores $/ \mathrm{ml}$ were not significant but significant with the check. Interaction of variety and inoculum concentration on the yield of cane inoculated with whip smut was similarly significant.

Table 3 also shows that Bida local treated with $6 \times 10^{6}$ teliospores $/ \mathrm{ml}$ inoculum concentration produced significantly $(p=0.01)$, less yield than the other treatments. The same variety treated with $6 \times 10^{6}$ teliospores/ml concentration produced less yield than the untreated check, but not Co 957 treated with $6 \times 10^{6}$ and $4 \times 10^{6}$ teliospores $/ \mathrm{ml}$ and $2 \times 10^{6}$ teliospores $/ \mathrm{ml}$.

Table 4 shows that at 3 MAP, Bida local and Co 957 treated with $6 \times 10^{6}$ teliospores $/ \mathrm{ml}$ significantly $(p=0.05)$ had the highest smut incidence than the significantly lower disease produced by the other inoculum treatments. The check gave the least disease incidence on the two test varieties. The same table also showed that Bida local treated with $6 \times 10^{6}$ teliospores $/ \mathrm{ml}$ inoculum concentration produced significantly $(p=0.01)$, less yield than the other treatments. The same variety treated with $6 \times 10^{6}$ teliospores/ml concentration produced lesser yield than untreated check, but not Co 957 treated with $6 \times 10^{6}$ and $4 \times 10^{6}$ teliospores $/ \mathrm{ml}$ and $2 \times 10^{6}$ teliospores $/ \mathrm{ml}$.

Table 4. Interaction of variety and inoculum concentration on smut incidence and cane yield of 1999 plant crop.

\begin{tabular}{|c|c|c|c|c|}
\hline \multirow{2}{*}{ Treatment } & \multicolumn{2}{|c|}{ \% Smutted stalks @ 3 MAP } & \multicolumn{2}{|c|}{ Cane yield (t/ha) } \\
\hline & Variety & & Variety & \\
\hline Teliospores/ml & Co 957 & Bida local & Co 957 & Bida local \\
\hline 0.0 & $0.0 \mathrm{~b}$ & $4.1 \mathrm{~b}$ & $91.2 \mathrm{a}$ & $57.7 d$ \\
\hline $2 \times 10^{6}$ & $1.6 \mathrm{~b}$ & $15.1 \mathrm{ab}$ & $86.5 b$ & $50.4 \mathrm{e}$ \\
\hline $4 \times 10^{6}$ & $1.5 \mathrm{~b}$ & $16.8 \mathrm{ab}$ & $82.8 \mathrm{c}$ & $35.7 \mathrm{f}$ \\
\hline $6 \times 10^{6}$ & $3.7 \mathrm{~b}$ & $25.8 \mathrm{a}$ & $79.7 \mathrm{c}$ & $24.7 \mathrm{~g}$ \\
\hline $\mathrm{SE} \pm$ & \multicolumn{2}{|c|}{2.70} & \multicolumn{2}{|c|}{3.80} \\
\hline
\end{tabular}

Means in a column followed by similar letter(s) are not significantly different at $p=0.05$, according to Duncan's Multiple Range Test (DMRT). 
Effects of inoculum concentration and sugar cane variety on whip smut incidence and yield, 2000 ratoon crop

Table 5 shows that at 3,6, 9 and 12 MAR, there was significantly higher incidence of smutted stools of Bida local than Co 957. Also at 3, 6, 9 and 12 MAR, the 2000RC had significant $(p=0.01)$ increase in disease of sugar cane whip smut on stools with increase in inoculum concentration. There was similarly, significant $(p=0.01)$ interaction of variety and inoculum concentration on incidence of smutted stools at 6 MAR.

Table 5 also shows that in 2000, there was no significant difference between the yield of Bida local and Co 957 . In contrast, the ratoon yield was significantly $(p=0.01)$ decreased with increase in inoculum concentration.
Interaction of variety and inoculum concentration was not significant.

\section{Regression of incidence of whip smut on cane yield of two crop cycles of sugar cane, 1998-2000}

Regression of whip smut incidence on cane yield for the two crop cycles of sugar cane (2PC and $2 \mathrm{RC}$ ) are shown in Table 6. In both crops, there was highly significant $(p=0.01)$ negative and linear correlation between the incidence of whip smut and cane yields, except in the case of the 1999 plant cane. The coefficient of determination $\left(\mathrm{r}^{2}\right)$ values was $0.9113,0.8222,0.9206$ and 0.4578 for 1998PC, 1999RC, 1999PC and 2000RC respectively. This indicated that $95.5,96.0,90.7$ and 67.7 $\%$ respectively, of the variations in cane yield were due to incidences of whip smut.

Table 5. Effects of variety and inoculum concentration on smut incidence and cane yield, 2000 ratoon crop.

\begin{tabular}{llllll}
\hline \multirow{2}{*}{ Treatment } & \% Smutted stools & & & & \\
\cline { 2 - 5 } & 3 MAR & 6 MAR & 9 MAR & 12 MAR & Yield (t/ha) \\
\hline Variety (V) & & & & & \\
Co 957 & $24.7 \mathrm{~b}$ & $36.5 \mathrm{~b}$ & $40.5 \mathrm{~b}$ & $42.9 \mathrm{~b}$ & $42.8 \mathrm{a}$ \\
Bida local & $39.4 \mathrm{a}$ & $56.1 \mathrm{a}$ & $57.7 \mathrm{a}$ & $60.3 \mathrm{a}$ & $47.1 \mathrm{a}$ \\
Mean & 32.1 & 46.3 & 49.6 & 51.6 & 45.0 \\
SE \pm & 1.60 & 1.50 & 1.00 & 1.30 & 10.20 \\
Sig. & $* *$ & $* *$ & $* *$ & $* *$ & $* *$ \\
Inoculum concentration (I) (teliospores/ml) & & & & \\
0.0 & $18.0 \mathrm{c}$ & $29.7 \mathrm{c}$ & $33.3 \mathrm{c}$ & $35.8 \mathrm{c}$ & $64.8 \mathrm{a}$ \\
$2 \times 10^{6}$ & $27.2 \mathrm{bc}$ & $41.6 \mathrm{~b}$ & $44.9 \mathrm{~b}$ & $46.9 \mathrm{~b}$ & $43.5 \mathrm{ab}$ \\
$4 \times 10^{6}$ & $36.1 \mathrm{ab}$ & $48.0 \mathrm{~b}$ & $49.5 \mathrm{~b}$ & $53.4 \mathrm{~b}$ & $38.1 \mathrm{ab}$ \\
$6 \times 10^{6}$ & $46.7 \mathrm{a}$ & $66.0 \mathrm{a}$ & $68.6 \mathrm{a}$ & $70.3 \mathrm{a}$ & $33.4 \mathrm{~b}$ \\
Mean & 32.0 & 46.3 & 49.1 & 51.6 & 45.0 \\
SE \pm & 3.80 & 3.20 & 3.40 & 3.50 & 7.00 \\
Sig. & $* *$ & $* *$ & $* *$ & $* *$ \\
Interaction & & & & & NS \\
V $\times$ I & $\mathrm{NS}$ & $* *$ & $\mathrm{NS}$ & $\mathrm{NS}$ & \\
\hline
\end{tabular}

Means followed by similar letter(s) are not significantly different at $p=0.01, p=0.05$ according to Duncan's Multiple Range

Test $(\mathrm{DMRT}) ;$ Sig. = significance, NS = Not significant, $*=$ Significant at $p=0.05, * *=$ Significant at $p=0.01$.

Table 6. Regression of whip smut incidence on cane yield of Co 957 and Bida local for two crop cycles, 1998,1999 and 2000.

\begin{tabular}{|c|c|c|c|c|c|c|}
\hline \multirow{2}{*}{ Year } & \multirow{2}{*}{ Crop cycle } & \multicolumn{5}{|c|}{ First year evaluation $1998-1999$} \\
\hline & & Variety & Regression equation & r-value & $\mathbf{r}^{2}$-value & Effect \\
\hline 1998 & Plant & Co 957 & $Y=139.25-1.9420 x$ & -0.6397 & 0.7598 & ** \\
\hline 1998 & Plant & Bida local & $Y=102.64-0.11066 x$ & -0.9639 & 0.9759 & ** \\
\hline 1999 & Ratoon & Co 957 & $Y=79.486-0.9657 x$ & -0.8012 & 0.8675 & $* *$ \\
\hline \multirow{2}{*}{1999} & Ratoon & Bida local & $Y=104.92-1.8570 x$ & -0.7946 & 0.8631 & $* *$ \\
\hline & & \multicolumn{5}{|c|}{ Second year evaluation $1999-2000$} \\
\hline 1999 & Plant & Co 957 & $Y=104.01-0.37744 x$ & -0.6599 & 0.7733 & *** \\
\hline 1999 & Plant & Bida local & $Y=159.43-1.8583 x$ & -0.9616 & 0.9744 & ** \\
\hline 2000 & Ratoon & Co 957 & $Y=67.424-0.57339 x$ & -0.1955 & 0.4637 & NS \\
\hline 2000 & Ratoon & Bida local & $Y=116.03-11427 x$ & -0.9952 & 0.9918 & ** \\
\hline
\end{tabular}

NS $=$ Not Significant $; * *=$ Significant at $p=0.01$ 
The relationship for the 1998PC, 1999RC, 1999PC and 2000RC are represented by the equations: $\mathrm{Y}=121.73-$ $1.4923 x, \quad Y=86.939-1.2839 x, \quad Y=109.50-0.8537 x$ and $\mathrm{Y}=136.00-1.6354 \mathrm{x}$ respectively. The $\mathrm{y}$-intercept was defined by the cane yield potential under disease free condition when the highest yield was attained. In the absence of the disease, therefore, cane yields were generally higher with the PCs in which approximately $121.7 \mathrm{t} / \mathrm{ha}$ was obtained from the $1998 \mathrm{PC}$ and $86.9 \mathrm{t} / \mathrm{ha}$ from the 1999RC and $136 \mathrm{t} / \mathrm{ha}$ from the $1999 \mathrm{PC}$ and $109.5 \mathrm{t} / \mathrm{ha}$, respectively. Thus, cane yields were lower in the RCs amounting to 86.9 t/ha in 1999 and 109 t/ha in 2000. In all, when sugar cane was not affected by whip smut, it yielded higher in the PCs than in the RC cycles. Cane yields were, therefore, higher by 40.0 and $24.2 \%$ in the first (1998-1999) and the second (1999-2000) year evaluations, respectively if sugar cane was kept free from whip smut.

Based on the slope of the regression line, the highest cane yield reduction from whip smut was obtained from the 2000RC, where each unit rise in disease incidence gave cane yield reduction of $1.6 \mathrm{t} / \mathrm{ha}$. Yield reduction for the 1998PC was $1.5 \mathrm{t} / \mathrm{ha}$; this was, however, higher than the yield reduction recorded from the $1999 \mathrm{RC}$ and PCs, $(1.3 \mathrm{t} / \mathrm{ha}$ and $0.9 \mathrm{t} / \mathrm{ha})$ respectively.

\section{Regression of whip smut incidence on cane yield in two sugar cane varieties for two crop cycles, 1998- 2000}

Regressions of whip smut incidence on cane yield of Co 957 and Bida local for two crop cycles are shown in Table 7. In both years, there was significant negative correlation between the incidence of whip smut and cane yield, except in 2000 on Co 957 ratoon crop. The coefficients of determination $\left(\mathrm{r}^{2}\right)$ values for the first year evaluation were between $0.7598-0.9759$ and $0.8661-0.8675$ for Co 957 and Bida plant and ratoon canes respectively. Similarly, for the second year evaluation in 1999, $\mathrm{r}^{2}$ values were between $0.7733-0.9744$ and $0.4637-0.9968$ for the plant and ratoon canes of the two varieties respectively. This, therefore, means that in the 1998 and 1999 evaluations, $76.00-97.6 \%$ and $86.3-86.8 \%$ respectively of the variations in the yields of the two cane varieties were due to the incidences of whip smut.

Table 7. Regression of whip smut incidence on cane yield of Co 957 and Bida local for two crop cycles, 1998, 1999 and 2000.

\begin{tabular}{|c|c|c|c|c|c|c|}
\hline \multirow{2}{*}{ Year } & \multirow{2}{*}{ Crop cycle } & \multicolumn{5}{|c|}{ First Year Evaluation 1998 - 1999} \\
\hline & & Variety & Regression equation & r-value & $\mathbf{r}^{2}$-value & Effect \\
\hline 1998 & Plant & Co 957 & $Y=139.25-1.9420 x$ & -0.6397 & 0.7598 & $* *$ \\
\hline 1998 & Plant & Bida local & $Y=102.64-0.11066 x$ & -0.9639 & 0.9759 & ** \\
\hline 1999 & Ratoon & Co 957 & $Y=79.486-0.9657 x$ & -0.8012 & 0.8675 & ** \\
\hline \multirow[t]{2}{*}{1999} & Ratoon & Bida local & $Y=104.92-1.8570 x$ & -0.7946 & 0.8631 & $* *$ \\
\hline & & \multicolumn{5}{|c|}{ Second Year Evaluation $1999-2000$} \\
\hline 1999 & Plant & Co 957 & $Y=104.01-0.37744 x$ & -0.6599 & 0.7733 & $* *$ \\
\hline 1999 & Plant & Bida local & $Y=159.43-1.8583 x$ & -0.9616 & 0.9744 & $* *$ \\
\hline 2000 & Ratoon & Co 957 & $Y=67.424-0.57339 x$ & -0.1955 & 0.4637 & NS \\
\hline 2000 & Ratoon & Bida local & $Y=116.03-11427 x$ & -0.9952 & 0.9918 & ** \\
\hline
\end{tabular}

NS $=$ Not Significant $; * *$ Significant at $p=0.01$

The y-intercept was defined by the cane yield potential under disease free condition when the highest cane yield was attained. In the absence of the disease in the 19981999 evaluation, yields of Co 957 were higher in the plant crop, where approximately 139.3 t/ha was recorded, except with Bida local in 1998 plant crop and its ratoon in 1999. On the contrary, in the 1999 evaluation, Bida local chewing sugar cane, under disease free condition, recorded higher cane yield than Co 957 in both the plant and ratoon crop cycles.

Generally, when canes were not affected by whip smut, the ratoon yields were higher than the plant crop, except with Bida local in 1998 and its ratoon of 1999.
Based on the slope of the regression equation, the highest yield reduction by whip smut was from the plant crop of Co 957 in 1998 and the ratoon crop of Bida local in 1999. In these crop cycles, each unit rise in whip smut $S$. scitamineum caused cane yield reduction of between 1.00-1.9 t/ha and 0.1-1.9 t/ha in Co 957 and Bida local respectively. In the 1999 evaluation, however, each unit rise in incidence of whip smut reduced the yield of Co 957 by $0.4-0.6 \mathrm{t} / \mathrm{ha}$ and by $1.1-1.9 \mathrm{t} / \mathrm{ha}$ in Bida local respectively. Thus, yield reduction by whip smut was generally higher in plant cane of Bida local than in Co 957, and generally higher in the ratoon canes, except with Co 957 in 1999 plant canes and Bida local in 2000 ratoon. 
Thus translated in monetary terms and at current rate of 1US\$ to 200 Nigerian Naira (N200), the cane grower of the two cane types looses between $\$ 600-1140 / t$ or N120,000-228,000 for Co 957 and $\$ 60-1140$ or N12000 - 228,000 for 'Bida local' chewing cane. In the 1999 evaluation, each unit rise in incidence of whip smut reduced the yield of Co 957 by $0.4-0.6$ t/ha which resulted in the cane grower of the two type sugar cane losing \$240-360/t or N144,000-216,000 for Co 957 and by $1.1-1.9 \mathrm{t} / \mathrm{ha}$ resulting in $\$ 660-1140$ loss/t or N132,000-684,000 for 'Bida local' respectively in the 1999-2000 crop cycles.

\section{Discussion}

The In achieving the objectives of the quantitative and monetary losses studies, two varieties of sugar cane, Co 957 and Bida local, of known susceptibility to $S$. scitamineum (Obakin, 1978; Wada et al., 1998 and 1999a) were evaluated from 1998 to 2000.

The yields of Bida local in all the two crop cycles from 1998 to 2000 were significantly lower than the yields of Co 957. Akobundu (1987) reported that the chewing sugar cane yields higher than the industrial sugar cane. The results from the present study are, therefore, at variance with the report by Akobundu (1987). This could be explained by the facts that this is an inoculated study where heavy inoculum loads were used and secondly the chewing sugar cane is hardly ratooned as the ratoon crop is heavily smutted with a resultant poor yield. In contrast, the Co 957, an industrial variety, in spite of heavy smut incidence survives and ratoons better with high yield. Thus, disease and variety differences between the two test cane varieties could account for the observed yield declines, particularly in their ratoon canes as well as the effect of $S$. scitamineum.

Also, the markedly reduced cane weights resulting from the highest inoculum concentration in this study supports the findings by several workers that smut infection reduces cane yield (Msechu and Keswani, 1982; Padmanaban et al., 1986; Hoy et al., 1986 and Kumar et al., 1989). Each of the inoculum concentrations recorded its own markedly reduced weight effect on the test canes corresponding to the strength of the inoculum present at the time of infection at inoculation. Differences in smut effect have been known to occur as a result of initial inoculum (Bergamin and Amorim, 1994; Comstock, 2014). Therefore, the observed significant differences on weights of infected canes in the present investigation are in line with the findings by other workers in other sugar cane producing areas such as Brazil where smut effects have been documented (Bergamin and Amorim, 1994). Whip smut caused significant loss of Co 957 and Bida local in all the two plant cycles between 1998 and 2000 in terms of reduced cane weight or tonnage yields of the two test canes by $0.4-0.6 \mathrm{t} / \mathrm{ha}$ and by $1.1-1.9 \mathrm{t} / \mathrm{ha}$ for Co 957 and Bida local respectively as elucidated by the regression analysis in the present study. The study shows that almost in all the years, there was significant negative correlation between the incidence of whip smut and cane yield. The coefficients of determination $\left(\mathrm{r}^{2}\right)$ values for the first year evaluation were between $0.7598-0.9759$ and 0.8661-0.8675 for Co 957 and Bida plant and ratoon canes respectively. Similarly, for the second year evaluation in 1999, $\mathrm{r}^{2}$ values were between 0.7733 0.9744 and $0.4637-0.9968$ for the plant and ratoon canes of the two varieties respectively. It can be deduced that in the 1998 and 1999 evaluations, 76.00-97.6\% and 86.3$86.8 \%$ respectively of the variations in the yields of the two cane varieties were due to the incidences of whip smut. The marked disease effect especially on the ratoon canes of Co 957 and Bida local could be as the result of established inoculum source for subsequent disease builds up from the inoculated or infected setts used in the study as observed by Comstock (2014).

The present work has thus established the first detailed documented evidence on the quantitative and monetary losses incited by $S$. scitamineum where it reduced the yields of Co 957 and Bida local in terms of percentages by $76.00-97.6 \%$ and $86.3-86.8 \%$ and in terms of tonnage by $0.4-0.6$ t/ha and by $1.1-1.9$ t/ha respectively . Thus, in monetary terms and at current rate of 1US\$ to 200 Nigerian Naira (N200), the cane grower of the two cane types looses between $\$ 600-1140 / \mathrm{t}$ or $\mathrm{N} 120,000-228,000$ for Co 957 and $\$ 60-1140$ or N12000 - 228,000 for 'Bida local' chewing cane. In the 1999 evaluation, each unit rise in incidence of whip smut reduced the yield of Co 957 by $0.4-0.6$ t/ha which resulted in the cane grower of the two type sugar cane losing $\$ 240-360 / \mathrm{t}$ or $\mathrm{N} 144,000-216,000$ for Co 957 and by $1.1-1.9 \mathrm{t} / \mathrm{ha}$ resulting in $\$ 660-1140 \mathrm{loss} / \mathrm{t}$ or N132,000-684,000 for 'Bida local' respectively in the 1999-2000 crop cycles.

Comstock (2014) reported that the extent of the yield and economic losses exerted on sugar cane by $S$. scitamineum are dependent primarily on the percentage of seed cane infected and by the yield loss of each infected plants. Therefore, in the present studies, each unit rise in $S$. scitamineum incidence reduced the yield of Co 957 in percentage by $95.5,96.0 \%$ and in tonnage by $0.4-0.6$ 
t/ha and by 1.1-1.9 t/ha particularly in Bida local chewing sugar cane.

\section{Conclusion}

The present study has elucidated the quantitative effect of different inoculum concentrations of Sporisorium scitamineum Sydow on of sugar cane in Nigeria. The study has shown that the extent of yield and economic losses in sugar cane are dependent primarily on the percentage of seed cane infected as this was an inoculated study and the yield loss of each infected plants have been documented. Equally, the monetary losses incurred by the grower of the two cane types have been quantified. Hence, proactive management strategies are needed to combat the recorded yield reduction effect and the monetary losses caused by S. scitamineum on the two cane varieties in the present study.

\section{Conflict of interest statement}

Authors declare that they have no conflict of interest.

\section{Acknowledgement}

The first author is appreciative of the financial and logistic support to him by the Executive Director, National Cereals Research Institute, Badeggi to undergo the studies on whip smut of sugar cane leading to the award of the Ph.D. degree of the University of Maiduguri, Maiduguri, Nigeria. The second author guided and supervised the first author and he thankfully acknowledges the University of Maiduguri Management for giving him the chance to supervise the work. The third author wrote the framework of the paper. All field and laboratory staff of NCRI are thanked for their respective efforts to see the study through successfully.

\section{References}

Akobundu, I.O., 1987. Sugar cane In: Weed Science in the Tropics: Principles and Practices (Ed.: Akobundu, I.O.). A Wiley - International Publication, Chrenag. John Wiley and Sons. pp.414-416.

Antonie, R., 1961. Smut. In: Sugar Cane Diseases of the World. Vol. 1 (Eds.: Martin, J. P., Abbott, E. V., Hughes, C. G.). Ellesmere Publishing Co., Amsterdam. pp.327345.

Bebee, C. N., 1988. The Protection of sugar cane and sugar Beets. Longman Inc., New York. pp.230-234.

Bergamin, A. F., Amorim, L., 1994. Effect of the initial inoculum of sugar cane smut development. In: Current Trends in Sugar Cane Pathology (Eds.: Rao, G.P. et al.). pp.49-58.

Boboye, S.O., 1986. Insect Pests of Sugar Cane in Nigeria and their Control. Lecture delivered at the One-Week Intensive Sugar cane production Training Course organized by the National Cereals Research Institute Badeggi, 2-7 November 1986.

Brar, R.S., 1988. Diseases of sugar cane. In: Pest Management (Ed.: Brar, R.S.). Nagmani Press, Ludhiana. pp.106-147.

Comstock, J. C., 2014. Seed cane transmissible diseases in sugarcane and their management. Souvenir de Presentation. International Conference IS-2014, Green Technologies for Sustainable Growth of Sugar \& Integrated Industries in Developing Countries, November 25-28, 2014, Nanning P. R. China. pp24-27.

Comstock, J. C., Wu, K. K., Tew, T. L., Ferreira, S. A., 1987. Sugar cane smut: Comparison of natural infection testing and artificial inoculation. Hawaiian Planters' Rec. 60(1), $1-7$.

Hill, D. S., Waller, J. U. M., 1988. Sugar cane. In: Pests and Diseases of Tropical Crops Gr. Field Handbook (Eds.: Hill D.S., Waller, J.M.). Longman Group, UK. pp.325337.

Hoy, J. W., Hollier, C. A., Fontenot, D. B., Grelen, L. B., 1986. Incidence of sugar cane smut in Louisiana and its effects on yield. Plant Dis. 70, 59-60.

Indi, D. V., Nalawade, S. V., Pawar, N., 2012. Stable sources of whip - smut resistance in sugarcane. Proc. Intl. Symp. New Paradigms in Sugar cane Research. Sugarcane Breeding Institute, Coimbatore, India. 15-18 October, 2012.

Irvine, J. E., 1982. Strategies for smut control. Sugarcane Path. Newsl. 28, 1-2.

James, W. C., 1983. Crop loss assessment. In: Path Pathologist's Pocketbook $2^{\text {nd }}$ Edn. (Eds.: Johnson, A., Booth, C.). CAB England. pp.130-143.

Kumar, S., Kumar, D., Sinha, R. N., 1989. Change in yield attributes, juice quality and mineral nutrients in cane juice due to smut infection. Indian Sugar. 39(4), 233-237.

Magarey, R. C., Bhuiyan, S., Croft, B. J., Cox, M. B., 2014. Development of smut resistant varieties and their economic impact on sugarcane production in Australia. Souvenir de Presentation. International Conference IS2014, Green Technologies for Sustainable Growth of Sugar \& Integrated Industries in Developing Countries, November 25-28, 2014, Nanning P. R. China, IS-2014, 92-93.

Msechu, Z. E., Keswani, C. L., 1982. Effect of sugar-cane smut on yield and yield components of sugar cane varieties in Tanzania. Trop. Agric. (Trinidad) 59(3), 243247.

Nasr, I. A., 1977. Standardization of inoculation techniques for sugar cane smut disease. Sugarcane Pathol. Newsl. 18, 2-5.

Obakin, F. O., 1978. Sugarcane improvement at National Cereals Research Institute. In: Proceeding of an International Symposium on Sugar cane in Nigeria NCRI, Moor Plantation, Ibadan, Nigeria, August 28 to September 
1, 1978. pp.12-16.

Ogunwolu, E. O., 1986. Comparative productivity of some exotic sugar cane varieties in the Southern Guinea Savannah of Nigeria. Nig. J. Agron. I (34), 110.

Padmanaban, R., Alexander, K. C., Shanmugan, N., 1988. Effect of smut on growth and yield parameters of sugar cane. Indian Phytopath. 41(3), 367-369.

Pearse, T. L., 1989. Influence of Roguing on the incidence of smut in Swaziland In: Proc. $63^{\text {rd }}$ Annual Congress of the South African Sugar Technologists' Association 1989. (58 June, 1989). Held at Durban and Mount Edgecombe, Natal South Africa. pp.115-121.

Sivanesan, A., Waller, J. M., 1986. Sugarcane Diseases. CMI Phytopath. Paper No. 29. CAB Int. Tarnham House, Slough SL23BN, UK. 88p.

Villalon, B., 1982. Sugar cane smut in Lower Rio Valley of South Texas. Plant Dis. 66, 605-606.

Wada, A. C., Abo, M. E., Agboire, S., Obakin, F. O., Okusanya, B. A., 1999a. Incidence, severity and distribution of sugarcane diseases in Nigeria. I. Southern
Guinea Savannah Zone. Discov. Innov. 11(1/2), 33-39.

Wada, A. C., Mian, M. A. W., Anaso, A.B., Busari, L. D., Kwon-Ndung, E. H., 1999b. Control of sugarcane Smut (Ustilago scitaminea Syd.) disease in Nigeria and suggestions for an integrated pest management approach. Sugar Tech. 1(3), 48-53.

Wada, A. C., 1997. Some important diseases and pests of sugarcane in Nigeria and their control. Outlook Agric. 26(2), 101-105.

Wada, A. C., Fademi, O. A., Misari, S. M., 1998. Assessment of sugarcane diseases and pests in ten Northern States and the Federal Capital Territory of Nigeria. Bangl. J. Sugarcane 18-20, 37-45.

Walker, D. I. T., 1987. Breeding for disease resistance. In: Development in Crop Science 11 Sugar cane Improvement through Breeding (Ed.: Heinz, D. M. J.). Elsevier, Amsterdam. 457p.

Whittle, A.M., 1982. Yield loss in sugarcane due to culmicolous smut infection. Trop. Agric. (Trinidad). 59(3), 239-242.

\section{How to cite this article:}

Wada, A. C., Anaso, A. B., Ehirim, B. O., 2016. Quantitative yield and monetary losses of two sugar cane varieties caused by whip smut (Sporisorium scitamineum H. \& P. Sydow) in Nigeria. Int. J. Curr. Res. Biosci. Plant Biol. 3(7), 11-21. doi: http://dx.doi.org/10.20546/ijcrbp.2016.307.003 